\title{
Seizures in Alzheimer's disease are highly recurrent and associated with a poor disease course
}

\author{
Jonathan Vöglein ${ }^{1,2}\left(\mathbb{0} \cdot\right.$ Ingrid Ricard $^{3} \cdot$ Soheyl Noachtar ${ }^{2} \cdot$ Walter A. Kukull $^{4} \cdot$ Marianne Dieterich $^{1,2,5,6}$. \\ Johannes Levin ${ }^{2,1,5} \cdot$ Adrian Danek $^{2,1}$
}

Received: 7 February 2020 / Revised: 18 May 2020 / Accepted: 19 May 2020 / Published online: 2 June 2020

(c) The Author(s) 2020

\begin{abstract}
Background Seizures are an important comorbidity in Alzheimer's disease (AD). Conflicting results regarding clinical parameters associated with seizures in AD were previously reported. Data on seizure recurrence risk, a crucial parameter for treatment decisions, are lacking.

Methods National Alzheimer's Coordinating Center data were analyzed. Seizure prevalence in AD and an association with disease duration were investigated. Associations of seizures with age of $\mathrm{AD}$ onset and with cognitive and functional performance, and seizure recurrence risk were studied.

Results 20,745 individuals were investigated. In AD dementia, seizure recurrence risk was $70.4 \%$ within 7.5 months. Seizure history was associated with an earlier age of onset of cognitive symptoms (seizures vs. no seizures: 64.7 vs. 70.4 years; $p<0.0001$ ) and worse cognitive and functional performance (mean MMSE score: 16.6 vs. 19.6; mean CDR-sum of boxes score: 9.3 vs. $6.8 ; p<0.0001$; adjusted for disease duration and age). Seizure prevalence increased with duration of AD dementia (standardized $\mathrm{OR}=1.55,95 \% \mathrm{CI}=1.39-1.73, p<0.0001$ ), rising from $1.51 \%$ at 4.8 years to $5.43 \%$ at 11 years disease duration. Seizures were more frequent in $\mathrm{AD}$ dementia compared to normal controls (active seizures: $1.51 \%$ vs. $0.35 \%$, $p<0.0001, \mathrm{OR}=4.34,95 \% \mathrm{CI}=3.01-6.27$; seizure history: $3.14 \%$ vs. $1.57 \%, p<0.0001, \mathrm{OR}=2.03,95 \% \mathrm{CI}=1.67-2.46$ ). Conclusion Seizures in AD dementia feature an exceptionally high recurrence risk and are associated with a poor course of cognitive symptoms. AD patients are at an increased risk for seizures, particularly in later disease stages. Our findings emphasize a need for seizure history assessment in $\mathrm{AD}$, inform individual therapeutic decisions and underline the necessity of systematic treatment studies of AD-associated epilepsy.
\end{abstract}

Keywords Alzheimer's disease $\cdot$ Epilepsy $\cdot$ Seizures $\cdot$ Seizure recurrence risk $\cdot$ Seizure prevalence

Johannes Levin

johannes.levin@med.uni-muenchen.de

$\triangle$ Adrian Danek

adrian.danek@med.uni-muenchen.de

1 German Center for Neurodegenerative Diseases (DZNE), Feodor-Lynen-Straße 17, 81377 Munich, Germany

2 Department of Neurology, Ludwig-Maximilians University, Marchioninistraße 15, 81377 Munich, Germany

3 Institute for Medical Informatics, Biometry and Epidemiology, Ludwig-Maximilians University, Marchioninistraße 15, 81377 Munich, Germany
4 Department of Epidemiology, University of Washington School of Public Health, 1959 NE Pacific Street, Seattle, WA 98195 , USA

5 Munich Cluster for Systems Neurology (SyNergy), Feodor-Lynen-Straße 17, 81377 Munich, Germany

6 German Center for Vertigo and Balance Disorders, Ludwig-Maximilians University, Marchioninistraße 15, 81377 Munich, Germany 


\section{Introduction}

In Alzheimer's disease (AD), cognitive symptoms represent the intrinsic clinical manifestation, but also non-cognitive symptoms affect individuals with $\mathrm{AD}[1,2]$. As the prevalence of $\mathrm{AD}$ is estimated to further increase in the future, there will be a mounting burden for patients and their families as well as for society [3]. Therefore, non-cognitive symptoms associated with $\mathrm{AD}$ will gain importance and will be needed to be addressed. Such a symptom are seizures. An association between Alzheimer's disease and seizures was reported in several studies with figures for seizure prevalence in $\mathrm{AD}$ from $0.5 \%$ up to $64 \%[4,5]$. In autosomal dominant $\mathrm{AD}$, that can be considered as a model disease of the sporadic form without age-associated comorbidities, there is an increased likelihood for the occurrence of seizures [2, 6], even very early in the disease course when cognitive impairment is absent [7]. A causal connection between $\mathrm{AD}$ and seizure pathophysiology is suggested by a number of mouse models for $\mathrm{AD}$, which frequently show epileptiform activity on EEG and overt seizures [8]. The National Alzheimer's Coordinating Center (NACC), established to facilitate collaborative research, runs a database that is unique for its size [9]. The clinical information entered follows the standardized manner of the Uniform Data Set (UDS) $[10,11]$. Open questions with respect to the recurrence risk of seizures in $\mathrm{AD}$ including potential consecutive treatment implications, regarding the connection between seizures and disease course as well as regarding the association of seizures with disease duration subsist. Using the NACC dataset, we aimed to investigate the clinical course of seizures and possible implications for antiepileptic treatment decisions.

\section{Methods}

\section{Participants}

The NACC database containing data from 34 past and present Alzheimer's disease centers (ADCs) in the USA was used for this study. Data of the UDS [10] from visits conducted between September 2005 and February 2016 were analyzed. NACC data has been described in detail before [8-12]. Research utilizing the NACC database was approved by the Institutional Review Board of the Ludwig-Maximilians University, Munich, Germany. Informed consent from individuals that are part of the NACC datasets was obtained at the respective ADCs.

\section{Assessment of seizures and AD stage}

In the UDS [10], occurrence of seizures is assessed by information obtained from the study participant and a mandatory co-participant interview, from medical records and from

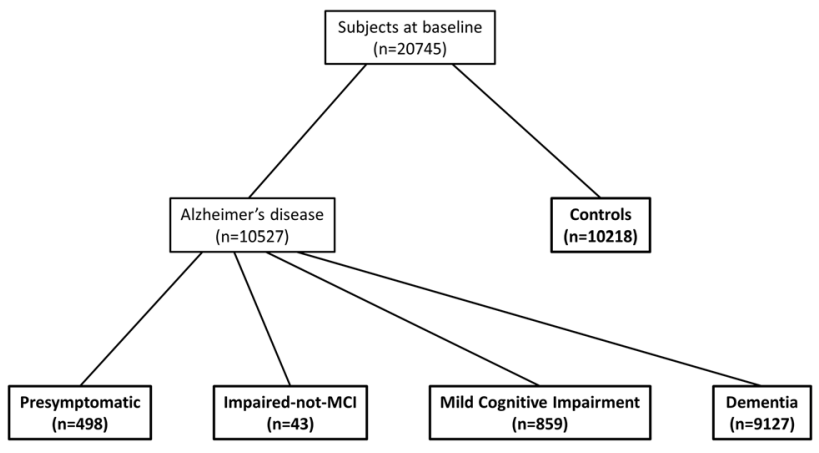

Fig. 1 Flow chart depicting the study population at baseline and separation into subgroups. For pre-symptomatic Alzheimer's disease, a normal cognitive status at baseline and a diagnosis of Alzheimer's disease dementia at follow-up was required. For impaired-not-MCI due to Alzheimer's disease and MCI due to Alzheimer's disease, both a presumptive etiologic diagnosis of Alzheimer's disease at baseline and a diagnosis of Alzheimer's disease dementia at follow-up were required. Groups that were included in analyses are shown in bold. MCImild cognitive impairment

observation. Four options are at choice: "Absent" (seizures are not indicated), "Recent/Active" (seizures happened within the last year or still require active management and are consistent with information obtained from the subject and co-participant interview), "Remote/Inactive" (seizures existed or occurred in the past-more than one year agobut were resolved or there is no treatment currently under way), or "Unknown" (insufficient information available from the subject and co-participant interview). From now on, if "Seizures" are stated "Recent/Active", they are referred to as active seizures.

The cognitive status is categorized in the NACC-UDS according to the four mutually exclusive options normal cognition, MCI (mild cognitive impairment), impaired-notMCI (subjects who are objectively cognitively impaired but who do not meet the criteria for MCI considering the subject's presentation, test results, symptoms, and clinical evaluation) or dementia. In subjects with any cognitive impairment (dementia, MCI, or impaired-not-MCI), the presumptive etiologic diagnosis is stated by the respective trained rater. For an etiologic diagnosis of AD, either the NINCDS/ADRDA (National Institute of Neurological and Communicative Disorders and Stroke/Alzheimer's Disease and Related Disorders Association) criteria [13] or the NIAAA (National Institute on Aging-Alzheimer's Association) criteria for AD dementia [14] were applied.

For analysis of seizure prevalence at baseline visits, we defined five groups. Presymptomatic AD (normal cognition at baseline), AD impaired-not-MCI, AD MCI, AD dementia, and controls (Fig. 1). The cognitive status of a participant is determined at every NACC study visit with the options "normal cognition", "impaired-not-MCI", "MCI" and "dementia" at choice. If a participant was attested 
"normal cognition" based on the overall impression taking all assessments of the respective visit into account by the respective trained clinical raters at all study visits (at baseline and follow-ups), she or he was allocated to the control group for this study. To increase the accuracy of the etiologic diagnosis of $\mathrm{AD}$ in cognitively impaired participants and to define the group with presymptomatic $\mathrm{AD}$, a diagnosis of $\mathrm{AD}$ dementia at a subsequent visit of the respective participant was stipulated for the classification into a pre-dementia stage of $\mathrm{AD}$.

\section{Clinical course of seizures in AD dementia}

In individuals with $\mathrm{AD}$ dementia at baseline, the prevalence of active seizures and disease duration at the baseline visit and 8 subsequent follow-up visits were calculated. To determine disease duration, each individual's age of onset of cognitive decline was subtracted from his or her age at the respective visit. The age of onset of cognitive decline is assessed for each participant in a standardized manner as part of UDS.

For assessment of seizure recurrence risk in $\mathrm{AD}$ dementia we calculated the proportion of patients with active seizures at the first follow-up visit of those who already suffered from active seizures at baseline and presented for follow-up. Cognitive and functional performance at baseline was compared between $\mathrm{AD}$ dementia patients with and without seizures.

\section{Statistical analyses}

Clinical and demographic features of the study population at baseline were analyzed and compared between subgroups using Fisher's exact test, Kruskal-Wallis test and Mann-Whitney $U$ test (Tables 1 and 2). Each AD group (presymptomatic, impaired-not-MCI, MCI, dementia) was compared to controls regarding the prevalence of active seizures and a history of seizures at baseline using Fisher's exact test (Fig. 4). In cases of statistically significant group differences, odds ratios (OR) and 95\% confidence intervals (CI) were calculated. Regarding a potential association between seizure prevalence and disease duration, different transformations of the disease duration were considered to improve the fit between the two variables. The best fit was provided by a logistic regression with disease duration square-transformed and standardized as explanatory variable (Fig. 3). For analysis of respective baseline cognitive and functional performance we compared $\mathrm{AD}$ dementia patients with and without seizures with respect to mean mini mental state examination (MMSE) [15] and clinical dementia rating-sum of boxes (CDR-SB) [16] scores in a generalized linear model with disease duration and age as co-variables. To assess the impact of seizures on the cognitive and functional trajectory as measured by CDR-SB, a general linear model with history of seizures (yes vs. no) and disease duration as independent variables and CDR-SB as dependent variable including a history of seizures*disease duration interaction was used. $p$ values below 0.05 were considered statistically significant. All tests were performed two-sided. The Statistical Package for the Social Sciences (IBM SPSS Statistics, Version 23) and R (version 3.5.1) were used for statistical analysis.

\section{Results}

\section{Participants}

We identified a total of 20,745 individuals with comprehensive clinical data at baseline (March 2016 NACC data freeze). Of these, 10,527 were diagnosed with $\mathrm{AD}$ and 10,218 were cognitively asymptomatic controls. 498 of the individuals with $\mathrm{AD}$ were classified, as described in the methods section, as pre-symptomatic, 43 as impaired-notMCI, 859 as MCI, and 9127 as demented (Fig. 1). Baseline characteristics of these subpopulations are shown in Table 1.

\section{Seizure recurrence risk}

At baseline $138 \mathrm{AD}$ dementia patients with active seizures were identified. After a mean of 7.46 months, 60 of them presented for follow-up (corresponding to a dropout rate of $56.5 \%$ ), and for 54 of these 60 data for seizures were available. Out of these 54 individuals, 38 still suffered from active seizures. These figures result in a risk for seizure recurrence of $70.4 \%$ within 7.46 months.

\section{Seizures, cognitive performance and age of AD onset}

With respect to cognition and function, AD dementia patients with a history of seizures performed worse in MMSE as well as in CDR-SB compared to those without (mean MMSE score: 16.6 vs. 19.6, $p<0.001$; mean CDR-SB score: 9.3 vs. $6.8, p<0.001$ ) after adjustment for disease duration and age (Table 2). There was a highly significant effect of a positive history of seizures on the CDR-SB towards abnormal over disease duration (history of seizures*disease duration: $F=18.66 ; p<0.001$ ) (Fig. 2). The age of onset of cognitive symptoms was earlier in $\mathrm{AD}$ dementia patients with seizures compared to those without (64.7 vs. 70.4 years, $p<0.001$ ).

\section{Disease duration and seizure prevalence}

The effect of disease duration on seizure prevalence was highly significant in patients with AD dementia 
Table 1 Study subpopulations, baseline characteristics and prevalence of seizures

\begin{tabular}{|c|c|c|c|c|c|c|}
\hline & $\begin{array}{l}\text { Pre-symptomatic } \\
\mathrm{AD}(n=498)\end{array}$ & $\begin{array}{l}\text { AD impaired- } \\
\text { not-MCI }(n=43)\end{array}$ & AD MCI $(n=859)$ & $\begin{array}{l}\text { AD dementia } \\
(n=9127)\end{array}$ & Controls $(n=10,218)$ & $p$ value \\
\hline Active seizures, No. (\%) & $2(0.4)$ & $1(2.33)$ & $1(0.12)$ & $138(1.51)$ & $36(0.35)$ & $<0.001^{1}$ \\
\hline History of seizures, No. (\%) & $9(1.8)$ & $1(2.33)$ & $11(1.28)$ & $287(3.14)$ & $161(1.57)$ & $<0.001^{1}$ \\
\hline Mean age $\pm S D$, years & $79.8 \pm 7.7$ & $74.9 \pm 9.0$ & $75.1 \pm 8.3$ & $75.1 \pm 9.9$ & $69.8 \pm 10.9$ & $<0.001^{2}$ \\
\hline Female: male, No. & $325: 173$ & 23: 20 & 427: 432 & 5140: 3987 & 6730: 3488 & $<0.001^{3}$ \\
\hline Mean MMSE score \pm SD & $28.2 \pm 1.8$ & $27.2 \pm 2.6$ & $26.1 \pm 2.7$ & $19.5 \pm 6.7$ & $28.9 \pm 1.4$ & $<0.001^{2}$ \\
\hline Mean CDR-SB score \pm SD & $0.3 \pm 0.6$ & $1.7 \pm 1.3$ & $1.9 \pm 1.2$ & $6.8 \pm 4.4$ & $0.1 \pm 0.3$ & $<0.001^{2}$ \\
\hline Mean global CDR score \pm SD & $0.10 \pm 0.20$ & $0.49 \pm 0.17$ & $0.51 \pm 0.11$ & $1.19 \pm 0.74$ & $0.04 \pm 0.14$ & $<0.001^{2}$ \\
\hline
\end{tabular}

$A D$ Alzheimer's Disease, $M C I$ mild cognitive impairment, $S D$ standard deviation, $M M S E$ Mini mental state examination, $C D R$ - $S B$ clinical dementia rating-sum of boxes

${ }^{1}$ Fisher's exact test comparing the groups AD dementia and controls. No statistically significant differences were found while comparing each other AD group to controls

${ }^{2}$ Kruskal-Wallis test comparing the groups pre-symptomatic AD, AD impaired-not-MCI, AD MCI, AD dementia and controls

${ }^{3}$ Pearson's Chi square test comparing the groups pre-symptomatic AD, AD impaired-not-MCI, AD MCI, AD dementia and controls

Table 2 Comparison of clinical and demographic baseline characteristic between Alzheimer's disease dementia patients with and without seizures

\begin{tabular}{|c|c|c|c|c|}
\hline & $\begin{array}{l}\text { AD dementia patients with } \\
\text { seizures }(n=287)\end{array}$ & $\begin{array}{l}\text { AD dementia patients without } \\
\text { seizures }(n=8840)\end{array}$ & Total $(n=9127)$ & $P$ value \\
\hline Mean age $\pm S D$, years & $71.1 \pm 10.9$ & $75.2 \pm 9.8$ & $75.1 \pm 9.9$ & $<0.001^{1}$ \\
\hline Female: male, No & 154: 133 & 4986: 3854 & 5140: 3987 & $0.36^{2}$ \\
\hline Mean age of onset $\pm S D$, years & $64.7 \pm 11.2$ & $70.4 \pm 9.9$ & $70.2 \pm 10.0$ & $<0.001^{1}$ \\
\hline Mean disease duration $\pm S D$, years & $6.3 \pm 4.1$ & $4.8 \pm 3.3$ & $4.8 \pm 3.4$ & $<0.001^{1}$ \\
\hline Mean MMSE score \pm SD & $16.6 \pm 8.6$ & $19.6 \pm 6.6$ & $19.5 \pm 6.7$ & $<0.001^{3}$ \\
\hline Mean CDR-SB score \pm SD & $9.3 \pm 5.8$ & $6.8 \pm 4.3$ & $6.8 \pm 4.4$ & $<0.001^{3}$ \\
\hline
\end{tabular}

$A D$ Alzheimer's disease, $S D$ standard deviation, $M M S E$ mini mental state examination, $C D R$ - $S B$ clinical dementia rating-sum of boxes

${ }^{1} p$ Value is derived from Mann-Whitney $U$ test

${ }^{2} p$ Value is derived from Fisher's exact test

${ }^{3}$ After adjustment for age and disease duration in a generalized linear model

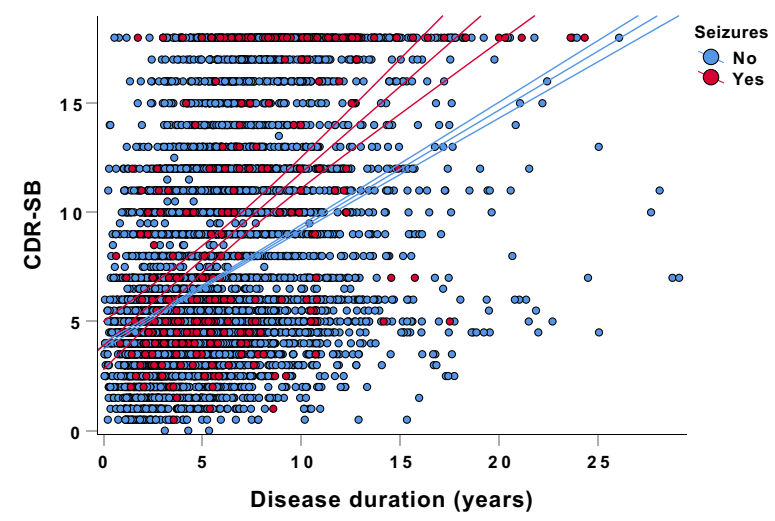

Fig. 2 Grouped scatter plot depicting CDR-SB as a function of the presence of a history of seizures and disease duration. There was a highly significant effect of the presence of a history of seizures on CDR-SB towards abnormal over disease duration. Middle lines represent the linear fits of the data, upper and lower lines represent $95 \%$ confidence intervals. $C D R$ - $S B$ clinical dementia rating-sum of boxes
( standardized OR $=1.55,95 \% \mathrm{CI}=1.39-1.73, p<0.001$ ). The frequency of active seizures amounted to $1.51 \%$ after 4.8 years of AD dementia duration and increased to $5.43 \%$ at 11.0 years of disease course. On average, prevalence of active seizures in $\mathrm{AD}$ dementia rose by $0.64 \%$ per year of disease duration (Fig. 3).

\section{Seizure prevalence}

Active seizures were significantly more prevalent in patients with AD dementia than in controls $(1.51 \%$ vs. $0.35 \%, \mathrm{OR}=4.34,95 \% \mathrm{CI}=3.01-6.27, p<0.001)$. Further, $\mathrm{AD}$ dementia patients revealed a history of seizures at a higher frequency compared to controls $(3.14 \%$ vs. $1.57 \%$, $\mathrm{OR}=2.03,95 \% \mathrm{CI}=1.67-2.46, p<0.001$ ) (Fig. 4).

No differences in the prevalence of active seizures were found in individuals with pre-symptomatic AD $(0.4 \%$, 


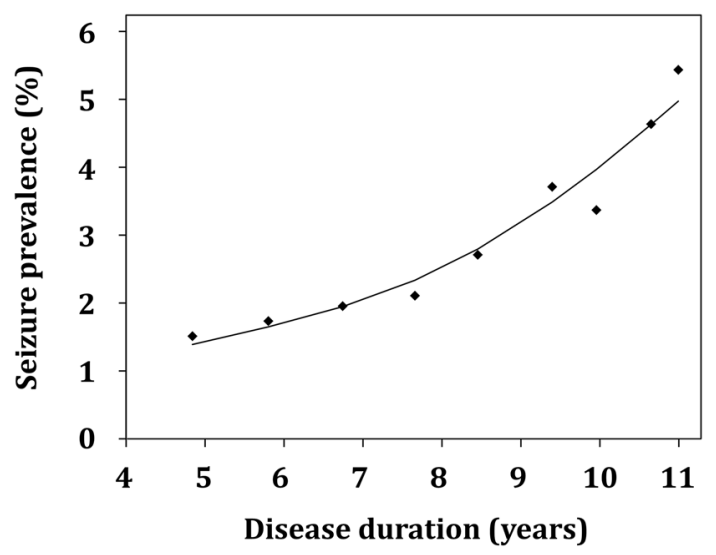

Fig. 3 Association of prevalence of active seizures and disease duration in patients with Alzheimer's disease dementia. Logistic regression with disease duration squared transformed and standardized as explanatory variable (Quadratic equation: logit $\{P($ "having a seizure"'Idisease duration $=d)\}=-3.56+0.44 \times\left(d-m_{\mathrm{d}} / \mathrm{sd}_{\mathrm{d}}\right)^{2}$ with $m_{\mathrm{d}}=72.7$ and $\mathrm{sd}_{\mathrm{d}}=35.0$ being the mean and the standard deviation over all disease durations). The effect of disease duration on seizure prevalence was highly significant in patients with $\mathrm{AD}$ dementia $(\mathrm{OR}=1.55,95 \% \mathrm{CI}=1.39-1.73, p<0.001)$

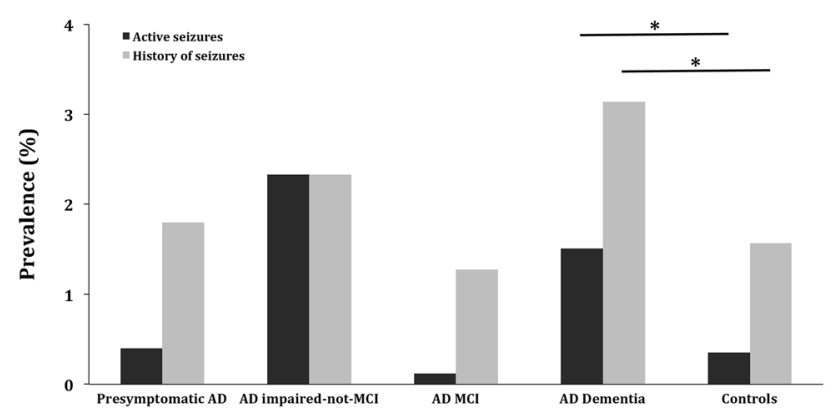

Fig. 4 Prevalence of seizures in the various stages of Alzheimer's disease and in controls. Prevalence of active seizures and a history of seizures were higher in $\mathrm{AD}$ dementia patients compared to controls. No differences in seizure prevalence in pre-dementia stages of $\mathrm{AD}$ compared to controls were found. $A D$ Alzheimer's disease, $M C I$ mild cognitive impairment. ${ }^{*} p<0.001$

$p=0.70)$, AD impaired-not-MCI $(2.33 \%, p=0.14)$ and $\mathrm{AD}$ MCI $(0.12 \%, p=0.36)$ compared to controls. With respect to a history of seizures, no differences between these groups were apparent (pre-symptomatic AD: $1.8 \%, p=0.71$; $\mathrm{AD}$ impaired-not-MCI: $2.33 \%, p=0.50$; AD MCI: $1.28 \%$, $p=0.67)$.

\section{Discussion}

In our analyses of the NACC database with nearly twentyone thousand individuals, standardized assessment of seizures with information obtained from study participants and their mandatory co-participants, from medical records and from observation, as well as $\mathrm{AD}$ diagnosis according to established criteria [13, 14], we revealed for the first time the exceptionally high recurrence risk for seizures of over $70 \%$ within about seven and half months in AD dementia patients. Based on this finding, it can be discussed that one unprovoked or reflex seizure should lead to the diagnosis of epilepsy in $\mathrm{AD}$ dementia according to the current guidelines of the International League Against Epilepsy (ILAE), which postulates a recurrence risk of at least $60 \%$ in ten years after a first unprovoked or reflex seizure for the diagnosis of epilepsy [17]. If AD dementia-associated epilepsy is diagnosed, the high recurrence risk as shown in our study should implicate the consideration of an antiepileptic treatment. It should also be noted, that the recurrence risk may be underestimated in this study as active seizures may prevent AD patients from further study participation. Additionally, a part of the evaluated individuals may already receive an antiepileptic medication mitigating seizure prevalence at follow-up. Further arguments for the consideration of an antiepileptic drug treatment are that $\mathrm{AD}$-associated seizures are responsive to a low dose monotherapy in many cases [17-21], and are associated with poor cognition and function as shown in this study as well as can accelerate cognitive decline [22, 23].

Of particular interest is the question if seizure recurrence risk is higher in $\mathrm{AD}$ than in older individuals with epilepsy without an overt neurodegenerative condition. In a recent study a recurrence risk within one year after a first unprovoked seizure of $53 \%$ in older individuals (mean age: 73 years; $\mathrm{AD}$ dementia patients with seizures in this study for comparison: 71 years) regardless of seizure etiology was reported [24]. These 53\% within one year compare to the $>70 \%$ within seven and a half months in AD-associated epilepsy as found in this study. An interpretation could be that $\mathrm{AD}$-associated epilepsy features a higher recurrence risk than seizures in older individuals with mixed seizure etiologies. However, it has to be considered that diagnosing of seizures in $\mathrm{AD}$ faces particular challenges. On the one hand, seizures can go unrecognized in $\mathrm{AD}$, i.e., due to memory problems of the respective patients. On the other hand, seizures can be wrongly suspected on the basis of cognitive fluctuations and other non-epileptic symptoms.

We found an association of seizures with worse cognitive and functional performance in $\mathrm{AD}$ dementia patients. This association may suggest that seizures promote cognitive decline in $\mathrm{AD}$. Another interpretation could be that $\mathrm{AD}$ patients who are more severely affected by cognitive deterioration are at an increased risk of seizures. However, we showed that $\mathrm{AD}$ patients with seizures performed worse in cognitive and functional tasks compared to patients without seizures after accounting for disease duration as a potential surrogate parameter of disease severity. This may also 
implicate the consideration of an antiepileptic treatment on an individual basis.

It is still unclear, if seizures are associated with an earlier age of $\mathrm{AD}$ onset [5]. The inverse association between prevalence of seizures and age of symptom onset of AD observed in this study may shed light on this lack of clarity. Our finding allows two interpretations. First, seizures may foster AD pathology $[25,26]$ and precipitate cognitive symptoms [22, 23]. Second, individuals with $A D$ at a younger age are more susceptible to seizures, i.e., feature a lower seizure threshold, compared to older individuals.

With respect to an association between AD severity and seizure risk, findings are at variance in the literature. Some studies suggest such an association [27, 28], whereas others showed an increased risk for seizures in AD that was independent from the disease stage $[29,30]$. Adding to clarification, we found a strong association between duration of $\mathrm{AD}$, i.e., the time from the onset of the first cognitive symptom, and the frequency of active seizures.

We confirmed and refined the increased risk for seizures in patients with $\mathrm{AD}$ dementia that was suggested previously $[4,5,31]$ in a large prospectively assessed dataset with $\mathrm{AD}$ diagnosis according to established criteria $[13,14]$ and standardized seizure assessment. The odds ratio of 4.34 for active seizures found fits well with the estimated two- to sixfold increase in seizure risk in $\mathrm{AD}$ patients of a recent review article [5]. Of note, the risk derived from the current analysis is more likely underestimated as seizures in the NACCUDS are assessed by only a single item [10]. Our results do not indicate that the predementia stage of AD carries an increased risk for seizures. This is particularly remarkable as we stipulated the diagnosis of AD dementia at a subsequent visit for the classification of the predementia stages to improve diagnostic accuracy. This finding is at odds with an increased seizure prevalence in the pre-symptomatic phase of autosomal dominant Alzheimer's disease (ADAD) [7]. A potential explanation could be that pathology in sporadic $\mathrm{AD}$ has to reach a higher threshold to increase seizure risk than in ADAD due to a higher susceptibility of the younger ADAD population for seizures. Another reason could be that the early pre-symptomatic seizures in ADAD are driven by mutation specific effects. However, also a reduced probing of raters in non-demented individuals in this study could be critical.

Both amyloid $\beta$ and tau, the neuropathological hallmarks of $\mathrm{AD}$, have been linked to seizure generation [5]. Mouse studies suggested a direct excitatory effect of amyloid $\beta$ on brain networks [32]. Our study showed an increased risk for seizures not before the dementia state of $\mathrm{AD}$ and a growing risk with disease duration. As tau pathology seems to be closely linked to the occurrence of cognitive symptoms [33], our findings could be in line with an obligatory presence of both amyloid $\beta$ and tau for seizure development and further could be in accordance with a proposed synergistic effect of these pathologies on the generation of seizures [34].

Strengths of our study are the large size of the cohort with over twenty thousand individuals in this investigation, yearly prospective data collection over more than a decade, and the standardized assessment with the well-validated UDS $[10,11]$. Limitations are that antiepileptic medication which can have an effect on seizure recurrence is not analyzed, semiology of seizures was not assessed, and with respect to the analysis of seizure recurrence risk the dropout rate of approximately $56 \%$. It can be discussed that the dropout rate may in part be caused by ongoing seizures restraining patients from further study participation. Further, the diagnosis of seizures in older individuals is challenging and their outcomes rely on self-report. Stroke history is not evaluated and therefore potential effects of strokes that did not prevent the affected participant from further study participation on seizure occurrence in our study population cannot be estimated precisely. As neuroimaging is not assessed, cortical lesions such as microhemorrhages or subclinical infarcts that could be contributing to the development of seizures cannot be ruled out. Additionally, there could be individuals with ADAD in the population of this study who are known to be at risk for seizures [36]. As the frequency of $\mathrm{ADAD}$ causing mutations in patients with $\mathrm{AD}$ is about or less than one percent [35] and the mean age of individuals with $\mathrm{AD}$ in this study (symptomatic AD: 75 years, presymptomatic $\mathrm{AD}: \sim 80$ years) corroborates the assumption that there is no substantial portion of individuals with ADAD in the study population, we did not perform analyses in detail regarding this subgroup that is expected to be very small.

In summary, in this study we reveal an exceptionally high recurrence risk of seizures in patients with $\mathrm{AD}$ dementia that should be considered in treatment of AD-associated seizures. Our results may answer open questions regarding an association of seizures with lower cognitive performance and a younger age of onset. A strong association between disease duration and seizure risk is demonstrated. Furthermore, the evidence for an increased seizure risk in AD dementia is confirmed and refined in a large cohort with consistently, prospectively assessed data.

Our findings corroborate the relevance and impact of seizures in clinical care of AD dementia, inform individual treatment decisions, and emphasize the necessity of prospective, double-blind, randomized, controlled, parallel-group antiepileptic treatment trials in $\mathrm{AD}$.

Acknowledgment Open Access funding provided by Projekt DEAL. The NACC database is funded by NIA/NIH Grant U01 AG016976. NACC data are contributed by the NIA-funded ADCs: P30 AG019610 (PI Eric Reiman, MD), P30 AG013846 (PI Neil Kowall, MD), P30 AG062428-01 (PI James Leverenz, MD) P50 AG008702 (PI Scott Small, MD), P50 AG025688 (PI Allan Levey, MD, PhD), P50 AG047266 (PI Todd Golde, MD, PhD), P30 AG010133 (PI Andrew Saykin, PsyD), P50 AG005146 (PI Marilyn Albert, PhD), P30 
AG062421-01 (PI Bradley Hyman, MD, PhD), P30 AG062422-01 (PI Ronald Petersen, MD, PhD), P50 AG005138 (PI Mary Sano, PhD), P30 AG008051 (PI Thomas Wisniewski, MD), P30 AG013854 (PI Robert Vassar, PhD), P30 AG008017 (PI Jeffrey Kaye, MD), P30 AG010161 (PI David Bennett, MD), P50 AG047366 (PI Victor Henderson, MD, MS), P30 AG010129 (PI Charles DeCarli, MD), P50 AG016573 (PI Frank LaFerla, PhD), P30 AG062429-01(PI James Brewer, MD, PhD), P50 AG023501 (PI Bruce Miller, MD), P30 AG035982 (PI Russell Swerdlow, MD), P30 AG028383 (PI Linda Van Eldik, PhD), P30 AG053760 (PI Henry Paulson, MD, PhD), P30 AG010124 (PI John Trojanowski, MD, PhD), P50 AG005133 (PI Oscar Lopez, MD), P50 AG005142 (PI Helena Chui, MD), P30 AG012300 (PI Roger Rosenberg, MD), P30 AG049638 (PI Suzanne Craft, PhD), P50 AG005136 (PI Thomas Grabowski, MD), P30 AG062715-01 (PI Sanjay Asthana, MD, FRCP), P50 AG005681 (PI John Morris, MD), P50 AG047270 (PI Stephen Strittmatter, MD, PhD). This work was funded by the Deutsche Forschungsgemeinschaft (DFG, German Research Foundation) under Germany's Excellence Strategy within the framework of the Munich Cluster for Systems Neurology (EXC 2145 SyNergy - ID 390857198).

\section{Compliance with ethical Standards}

Conflict of interest Johannes Levin reports speaker fees from Bayer Vital, consulting fees from Axon Neuroscience and Ionis Pharmaceuticals, author fees from Thieme medical publishers and W. Kohlhammer GmbH medical publishers, non-financial support from Abbvie and compensation for duty as part-time CMO from MODAG, outside the submitted work. Adrian Danek receives funding from Advocacy for Neuroacanthocytosis Patients and received speaker honoraria from The International Parkinson and Movement Disorder Society, Clienia Schlössli AG, Blutspende Zürich, Kantonsspital Aarau AG, München Klinik, and Bayer. He serves as an editorial board member of Translational Neuroscience. All other authors report no conflict of interest.

Ethical approval All procedures performed in studies involving human participants were in accordance with the ethical standards of the institutional and/or national research committee and with the 1964 Helsinki declaration and its later amendments or comparable ethical standards.

Open Access This article is licensed under a Creative Commons Attribution 4.0 International License, which permits use, sharing, adaptation, distribution and reproduction in any medium or format, as long as you give appropriate credit to the original author(s) and the source, provide a link to the Creative Commons licence, and indicate if changes were made. The images or other third party material in this article are included in the article's Creative Commons licence, unless indicated otherwise in a credit line to the material. If material is not included in the article's Creative Commons licence and your intended use is not permitted by statutory regulation or exceeds the permitted use, you will need to obtain permission directly from the copyright holder. To view a copy of this licence, visit http://creativecommons.org/licenses/by/4.0/.

\section{References}

1. Albers MW, Gilmore GC, Kaye J, Murphy C, Wingfield A, Bennett DA, Boxer AL, Buchman AS, Cruickshanks KJ, Devanand DP, Duffy CJ, Gall CM, Gates GA, Granholm AC, Hensch T, Holtzer R, Hyman BT, Lin FR, McKee AC, Morris JC, Petersen RC, Silbert LC, Struble RG, Trojanowski JQ, Verghese J, Wilson DA, Xu S, Zhang LI (2015) At the interface of sensory and motor dysfunctions and Alzheimer's disease. Alzheimer Dementia 11(1):70-98. https://doi.org/10.1016/j.jalz.2014.04.514

2. Tang M, Ryman DC, McDade E, Jasielec MS, Buckles VD, Cairns NJ, Fagan AM, Goate A, Marcus DS, Xiong C, Allegri RF, Chhatwal JP, Danek A, Farlow MR, Fox NC, Ghetti B, Graff-Radford NR, Laske C, Martins RN, Masters CL, Mayeux RP, Ringman JM, Rossor MN, Salloway SP, Schofield PR, Morris JC, Bateman RJ (2016) Neurological manifestations of autosomal dominant familial Alzheimer's disease: a comparison of the published literature with the Dominantly Inherited Alzheimer Network observational study (DIAN-OBS). Lancet Neurol 15(13):1317-1325. https:// doi.org/10.1016/s1474-4422(16)30229-0

3. Scheltens P, Blennow K, Breteler MM, de Strooper B, Frisoni GB, Salloway S, Van der Flier WM (2016) Alzheimer's disease. Lancet (Lond, Engl) 388(10043):505-517. https://doi.org/10.1016/s0140 $-6736(15) 01124-1$

4. Horvath A, Szucs A, Barcs G, Noebels JL, Kamondi A (2016) Epileptic seizures in alzheimer disease: a review. Alzheimer Dis Assoc Disord 30(2):186-192. https://doi.org/10.1097/wad.00000 00000000134

5. Nicastro N, Assal F, Seeck M (2016) From here to epilepsy: the risk of seizure in patients with Alzheimer's disease. Epileptic Disord Int Epilepsy J Videotape 18(1):1-12. https://doi.org/10.1684/ epd.2016.0808

6. Vöglein J, Willem M, Trambauer J, Schönecker S, Dieterich M, Biskup S, Giudici C, Utz K, Oberstein T, Brendel M, Rominger A, Danek A, Steiner H, Haass C, Levin J (2019) Identification of a rare presenilin 1 single amino acid deletion mutation (F175del) with unusual amyloid- $\beta$ processing effects. Neurobiology of Aging 84:241.e245-241.e211. https://doi.org/10.1016/j.neuro biolaging.2019.08.034

7. Vöglein J, Noachtar S, McDade E, Quaid KA, Salloway S, Ghetti B, Noble J, Berman S, Chhatwal J, Mori H, Fox N, Allegri R, Masters CL, Buckles V, Ringman JM, Rossor M, Schofield PR, Sperling R, Jucker M, Laske C, Paumier K, Morris JC, Bateman RJ, Levin J, Danek A (2018) Seizures as an early symptom of autosomal dominant Alzheimer's disease. Neurobiol Aging 76:18-23. https://doi.org/10.1016/j.neurobiolaging.2018.11.022

8. Born HA (2015) Seizures in Alzheimer's disease. Neuroscience 286:251-263. https://doi.org/10.1016/j.neuroscience.2014.11.051

9. Beekly DL, Ramos EM, van Belle G, Deitrich W, Clark AD, Jacka ME, Kukull WA (2004) The National Alzheimer's Coordinating Center (NACC) database: an alzheimer disease database. Alzheimer Dis Assoc Disord 18(4):270-277

10. Morris JC, Weintraub S, Chui HC, Cummings J, Decarli C, Ferris S, Foster NL, Galasko D, Graff-Radford N, Peskind ER, Beekly D, Ramos EM, Kukull WA (2006) The uniform data set (UDS): clinical and cognitive variables and descriptive data from Alzheimer Disease Centers. Alzheimer Dis Assoc Disord 20(4):210-216. https://doi.org/10.1097/01.wad.0000213865.09806.92

11. Beekly DL, Ramos EM, Lee WW, Deitrich WD, Jacka ME, Wu J, Hubbard JL, Koepsell TD, Morris JC, Kukull WA (2007) The national alzheimer's coordinating center (NACC) database: the uniform data set. Alzheimer Dis Assoc Disord 21(3):249-258. https://doi.org/10.1097/WAD.0b013e318142774e

12. Weintraub S, Salmon D, Mercaldo N, Ferris S, Graff-Radford NR, Chui H, Cummings J, DeCarli C, Foster NL, Galasko D, Peskind E, Dietrich W, Beekly DL, Kukull WA, Morris JC (2009) The alzheimer's disease centers' uniform data set (UDS): the neuropsychological test battery. Alzheimer Dis Assoc Disord 23(2):91-101. https://doi.org/10.1097/WAD.0b013e318191c7dd

13. McKhann G, Drachman D, Folstein M, Katzman R, Price D, Stadlan EM (1984) Clinical diagnosis of Alzheimer's disease: report of the NINCDS-ADRDA Work Group under the auspices 
of Department of Health and Human Services Task Force on Alzheimer's Disease. Neurology 34(7):939-944

14. McKhann GM, Knopman DS, Chertkow H, Hyman BT, Jack CR Jr, Kawas CH, Klunk WE, Koroshetz WJ, Manly JJ, Mayeux R, Mohs RC, Morris JC, Rossor MN, Scheltens P, Carrillo MC, Thies B, Weintraub S, Phelps CH (2011) The diagnosis of dementia due to Alzheimer's disease: recommendations from the National Institute on Aging-Alzheimer's Association workgroups on diagnostic guidelines for Alzheimer's disease. Alzheimer Dementia 7(3):263-269. https://doi.org/10.1016/j.jalz.2011.03.005

15. Folstein MF, Folstein SE, McHugh PR (1975) "Mini-mental state". A practical method for grading the cognitive state of patients for the clinician. J Psychiatric Res 12(3):189-198

16. Morris JC (1993) The clinical dementia rating (CDR): current version and scoring rules. Neurology 43(11):2412-2414

17. Fisher RS, Acevedo C, Arzimanoglou A, Bogacz A, Cross JH, Elger CE, Engel J Jr, Forsgren L, French JA, Glynn M, Hesdorffer DC, Lee BI, Mathern GW, Moshe SL, Perucca E, Scheffer IE, Tomson T, Watanabe M, Wiebe S (2014) ILAE official report: a practical clinical definition of epilepsy. Epilepsia 55(4):475-482. https://doi.org/10.1111/epi.12550

18. Vossel KA, Beagle AJ, Rabinovici GD, Shu H, Lee SE, Naasan G, Hegde M, Cornes SB, Henry ML, Nelson AB, Seeley WW, Geschwind MD, Gorno-Tempini ML, Shih T, Kirsch HE, Garcia PA, Miller BL, Mucke L (2013) Seizures and epileptiform activity in the early stages of Alzheimer disease. JAMA Neurol 70(9):1158-1166. https://doi.org/10.1001/jamaneurol.2013.136

19. Cretin B, Sellal F, Philippi N, Bousiges O, Di Bitonto L, MartinHunyadi C, Blanc F (2016) Epileptic prodromal alzheimer's disease, a retrospective study of 13 new cases: expanding the spectrum of alzheimer's disease to an epileptic variant? J Alzheimer's Dis 52(3):1125-1133. https://doi.org/10.3233/jad-150096

20. Sarkis RA, Dickerson BC, Cole AJ, Chemali ZN (2016) Clinical and neurophysiologic characteristics of unprovoked seizures in patients diagnosed with dementia. J Neuropsychiatry Clin Neurosci 28(1):56-61. https://doi.org/10.1176/appi.neuropsych.15060 143

21. Cumbo E, Ligori LD (2010) Levetiracetam, lamotrigine, and phenobarbital in patients with epileptic seizures and Alzheimer's disease. Epilepsy Behavior 17(4):461-466. https://doi.org/10.1016/j. yebeh.2010.01.015

22. Volicer L, Smith S, Volicer BJ (1995) Effect of seizures on progression of dementia of the Alzheimer type. Dementia (Basel, Switzerl) 6(5):258-263

23. Lott IT, Doran E, Nguyen VQ, Tournay A, Movsesyan N, Gillen DL (2012) Down syndrome and dementia: seizures and cognitive decline. J Alzheimer's Dis 29(1):177-185. https://doi. org/10.3233/jad-2012-111613

24. Lawn N, Kelly A, Dunne J, Lee J, Wesseldine A (2013) First seizure in the older patient: clinical features and prognosis. Epilepsy Res 107(1-2):109-114. https://doi.org/10.1016/j.eplepsyres .2013.08.009

25. Yamamoto K, Tanei ZI, Hashimoto T, Wakabayashi T, Okuno H, Naka Y, Yizhar O, Fenno LE, Fukayama M, Bito H, Cirrito JR, Holtzman DM, Deisseroth K, Iwatsubo T (2015) Chronic optogenetic activation augments abeta pathology in a mouse model of Alzheimer disease. Cell Rep 11(6):859-865. https:// doi.org/10.1016/j.celrep.2015.04.017
26. Wu JW, Hussaini SA, Bastille IM, Rodriguez GA, Mrejeru A, Rilett K, Sanders DW, Cook C, Fu H, Boonen RA, Herman M, Nahmani E, Emrani S, Figueroa YH, Diamond MI, Clelland CL, Wray S, Duff KE (2016) Neuronal activity enhances tau propagation and tau pathology in vivo. Nat Neurosci 19(8):1085-1092. https://doi.org/10.1038/nn.4328

27. Romanelli MF, Morris JC, Ashkin K, Coben LA (1990) Advanced Alzheimer's disease is a risk factor for late-onset seizures. Arch Neurol 47(8):847-850

28. Irizarry MC, Jin S, He F, Emond JA, Raman R, Thomas RG, Sano M, Quinn JF, Tariot PN, Galasko DR, Ishihara LS, Weil JG, Aisen PS (2012) Incidence of new-onset seizures in mild to moderate Alzheimer disease. Arch Neurol 69(3):368-372. https ://doi.org/10.1001/archneurol.2011.830

29. Amatniek JC, Hauser WA, DelCastillo-Castaneda C, Jacobs DM, Marder K, Bell K, Albert M, Brandt J, Stern Y (2006) Incidence and predictors of seizures in patients with Alzheimer's disease. Epilepsia 47(5):867-872. https://doi.org/10.111 1/j.1528-1167.2006.00554.x

30. Bernardi S, Scaldaferri N, Vanacore N, Trebbastoni A, Francia A, D'Amico A, Prencipe M (2010) Seizures in Alzheimer's disease: a retrospective study of a cohort of outpatients. Epileptic Disord 12(1):16-21. https://doi.org/10.1684/epd.2010.0290

31. Friedman D, Honig LS, Scarmeas N (2012) Seizures and epilepsy in Alzheimer's disease. CNS Neurosci Ther 18(4):285-294. https ://doi.org/10.1111/j.1755-5949.2011.00251.x

32. Palop JJ, Chin J, Roberson ED, Wang J, Thwin MT, Bien-Ly N, Yoo J, Ho KO, Yu GQ, Kreitzer A, Finkbeiner S, Noebels JL, Mucke L (2007) Aberrant excitatory neuronal activity and compensatory remodeling of inhibitory hippocampal circuits in mouse models of Alzheimer's disease. Neuron 55(5):697-711. https:// doi.org/10.1016/j.neuron.2007.07.025

33. Gordon BA, Blazey TM, Christensen J, Dincer A, Flores S, Keefe S, Chen C, Su Y, McDade EM, Wang G, Li Y, Hassenstab J, Aschenbrenner A, Hornbeck R, Jack CR, Ances BM, Berman SB, Brosch JR, Galasko D, Gauthier S, Lah JJ, Masellis M, van Dyck CH, Mintun MA, Klein G, Ristic S, Cairns NJ, Marcus DS, Xiong C, Holtzman DM, Raichle ME, Morris JC, Bateman RJ, Benzinger TLS (2019) Tau PET in autosomal dominant Alzheimer's disease: relationship with cognition, dementia and other biomarkers. Brain J Neurol 142(4):1063-1076. https://doi.org/10.1093/ brain/awz019

34. Roberson ED, Hope OA, Martin RC, Schmidt D (2011) Geriatric epilepsy: research and clinical directions for the future. Epilepsy Behavior 22(1):103-111. https://doi.org/10.1016/j.yebeh .2011.04.005

35. Bateman RJ, Xiong C, Benzinger TL, Fagan AM, Goate A, Fox NC, Marcus DS, Cairns NJ, Xie X, Blazey TM, Holtzman DM, Santacruz A, Buckles V, Oliver A, Moulder K, Aisen PS, Ghetti B, Klunk WE, McDade E, Martins RN, Masters CL, Mayeux R, Ringman JM, Rossor MN, Schofield PR, Sperling RA, Salloway S, Morris JC (2012) Clinical and biomarker changes in dominantly inherited Alzheimer's disease. N Engl J Med 367(9):795-804. https://doi.org/10.1056/NEJMoa1202753

36. Cortini F, Cantoni C, Villa C (2018) Epileptic seizures in autosomal dominant forms of Alzheimer's disease. Seizure 61:4-7. https ://doi.org/10.1016/j.seizure.2018.07.015 